\title{
Signal detection comparisons of phonemic and phonetic priming: The flexible-bias problem
}

\author{
STEPHEN D. GOLDINGER \\ Arizona State University, Tempe, Arizona
}

\begin{abstract}
The phonemic priming effect may reflect the hidden dynamics of spoken word perception and has thus been a key topic of recent research. This investigation compared phonemic and phonetic priming (cf. Goldinger, Luce, Pisoni, \& Marcario, 1992), using signal detection methods. Although these methods were intended to provide separate indices of sensitivity and bias changes, the results were more complex. Instead, phonemic priming engendered a flexible, trial-specific strategy that affected hits and false alarms (and thereby altered sensitivity) but also created behavioral changes indicative of a bias. Together with previous research, the results suggest that phonemic priming data must be interpreted with caution, and they underscore the limitations of signal detection analyses in priming research (Norris, 1995). However, if a researcher can anticipate the likely form a bias will assume, signal detection methods can reveal priming effects.
\end{abstract}

Relative to the voluminous literature on semantic priming effects in printed and spoken word perception, formbased priming has received little attention. Form-based priming refers to experiments in which primes and targets are related along physical, rather than conceptual, dimensions. For example, whereas doctor-nurse is a semantic prime-target pair by virtue of related meanings (Collins \& Loftus, 1975; Meyer \& Schvaneveldt, 1971), north-nurse is a form-based prime-target pair by virtue of common initial letters (in a visual task) or phonemes (in an auditory task). The present research concerns formbased priming of spoken words, specifically phonemic priming effects and their comparison with phonetic priming effects (Goldinger, Luce, Pisoni, \& Marcario, 1992). Many current models of spoken word perception are framed as dynamic processes of activation and competition, with each process guided by physical stimulus dimensions (Luce, Pisoni, \& Goldinger, 1990; MarslenWilson, 1990; McClelland \& Elman, 1986). As such, form-based priming may help elucidate the covert dynamics of word perception.

\section{Phonemic Priming}

Phonemic priming is observed when perception of a spoken target (e.g., nurse) is modified by prior perception of a related prime (e.g., north), relative to an unrelated

\footnotetext{
Support was provided by Grant R29-DC02629-02 from the National Institute for Deafness and Other Communicative Disorders (NIDCD). I thank Marianne Abramson, Brian Smith, Kristin Magin, and Vanessa Hendrichs for research assistance and Rob Nosofsky for suggesting the signal detection approach. Helpful comments on prior drafts were provided by Tamiko Azuma, Paul Luce, Jim Neely, Dennis Norris, Michael Masson, Todd Maddox, and Louisa Slowiaczek. Please address correspondence to S. D. Goldinger, Department of Psychology, Arizona State University, Box 871104, Tempe, AZ 85287-1104 (e-mail: goldinger@) asu.edu).
}

prime (e.g., wedge). To date, the phonemic priming literature contains fairly inconsistent findings (see Radeau, Morais, \& Segui, 1995, Appendix A). Slowiaczek, Nusbaum, and Pisoni (1987) examined identification of primed and unprimed words. In this method, a clear spoken prime is presented, followed by a variable interstimulus interval (ISI) and a degraded target; identification accuracy is examined. In Slowiaczek et al.'s experiments, targets were presented at five signal-to-noise $(\mathrm{S} / \mathrm{N})$ ratios, and degrees of prime-target overlap were varied, ranging from zero to four phonemes. In three experiments, they observed facilitatory priming that increased both as the $\mathrm{S} / \mathrm{N}$ ratio decreased (more noise) and as prime-target overlap increased.

From these results, Slowiaczek et al. (1987) offered two conclusions: Word perception involves segmental analysis, and it involves shared activation among candidate words. Although these are common claims (Luce, 1986: Marslen-Wilson, 1990; Paap, Newsome, McDonald, \& Schvaneveldt, 1982), phonemic priming has proven to be fairly controversial. First, it does not easily replicate in reaction time (RT) tasks: Slowiaczek and Pisoni (1986) examined primed lexical decision, using procedures similar to those described above. Although repetition primes reliably facilitated performance, no priming occurred for pairs sharing one, two, or three phonemes. Slowiaczek and Pisoni noted that lexical decision entails a small response set, clear stimuli, and time pressure. These factors may dissuade subjects from using prime information and may render lexical decision insensitive to priming, relative to the identification task. Conversely, the lexical decision data may reflect a true lack of phonemic priming. Because the identification task imposes no time constraints, listeners may use prime information to help infer the degraded targets - a guessing strategy. Indeed, this would explain why Slowiaczek et al. (1987) found stronger priming when targets were more degraded. 
Radeau, Morais, and Dewier (1989) further investigated phonemic priming, using lexical decision and shadowing tasks. The lexical decision methods were similar to those of Slowiaczek and Pisoni (1986), employing brief ISIs and clear stimuli. The shadowing methods differed only in elicited responses. Radeau et al. (1989) observed no facilitation (except repetition priming) in any experiment. Indeed, they occasionally observed inhibition, primarily in lexical decision. Given that phonemic priming did not generalize across tasks, Radeau et al. suggested that Slowiaczek et al.'s (1987) findings could be artifactual. They also endorsed shadowing as a "validating task" in spoken word perception, used to scrutinize effects from tasks with extensive postaccess processing (Balota \& Chumbley, 1984). Radeau et al. (1995) recently extended this shadowing research, comparing effects of phonemic overlap in word-initial, as opposed to wordfinal, positions. They observed reliable facilitation for word-final priming, but word-initial overlap yielded either no priming or weak inhibition.

The Radeau et al. (1995) results are complemented by other shadowing data. Slowiaczek and Hamburger (1992) examined primed shadowing, with primes and targets that shared varying degrees of overlap, ranging from zero to four phonemes. On finding both facilitatory (one-phoneme overlap) and inhibitory (two- to three-phoneme overlap) priming, Slowiaczek and Hamburger proposed a connectionist model that entailed prelexical excitation and wordlevel inhibition. This account resembles several models in the literature (Goldinger, Luce, \& Pisoni, 1989; MarslenWilson, 1990; McClelland \& Elman, 1986) and suggests that capricious phonemic priming effects may simply reflect complex lexical dynamics. In a later test, Hamburger and Slowiaczek (1996) examined primed shadowing in conditions that varied the likely contributions of response bias. For high-expectancy subjects, the method involved a long $(500-\mathrm{msec})$ ISI and a high (75\%) proportion of related trials. Low-expectancy subjects received a short (50-msec) ISI and a low (21\%) proportion of related trials. In the high-expectancy condition, the prior results were replicated - facilitation for one-phoneme overlap, mixed with inhibition for two- and three-phoneme overlap. In the low-expectancy condition, the facilitation effect vanished, but the inhibition remained. Taken together, the data suggested that weak priming effects are bias-based but that stronger priming effects are lexically based (see Goldinger, in press, for qualifications).

\section{Phonetic (Feature) Priming}

The inhibitory priming observed by Radeau et al. (1989; Hamburger \& Slowiaczek, 1996' makes sense, considering findings reported by Goldinger et al. (1989). Like Slowiaczek et al. (1987), we examined primed identification of words in noise. However, we used prime-target pairs that were phonetically similar (when presented in noise) but shared no common phonemes, such as ROBLOPE. Thus, priming was based on shared phonetic features (henceforth feature priming) and it was inhibitory, relative to unrelated primes. However, inhibition only occurred when a $50-\mathrm{msec}$ ISI was used, vanishing when the ISI was increased to $500 \mathrm{msec}$. Also, inhibition only occurred when targets followed low-frequency primes, vanishing when targets followed high-frequency primes. These constraints on feature priming are consistent with models assuming transient competition among words; in conditions that allow prime activation to dissipate (by using a long ISI or rapidly processed high-frequency primes), competition fades and target perception returns to baseline levels.

Phonemic- and feature-priming effects seem mutually inconsistent, as both effects have been explained by reference to lexical (or prelexical) activation. However, such opposite effects can arise in a unitary system, such as the interactive-activation model (McClelland \& Rumelhart, 1981). Specifically, phoneme nodes could receive excitation from feature and word levels, and could inhibit each other. Consider the recognition of the word $/ \mathrm{bIn} /$, following the primes /bæt/ or /pæt/: After recognition of /bæt/, the phoneme $/ \mathrm{b} /$ briefly remains activated, encouraging later recognition of $/ \mathrm{bIn} /$ - a phonemic priming effect. Conversely, because $/ \mathrm{b} /$ and $/ \mathrm{p} /$ are phonetically similar, recognition of /pæt/ will briefly suppress the /b/ nodea feature-priming effect.

\section{Comparing Phonemic and Feature Priming}

The interactive-activation model shows that phonemic and feature priming are explicable, but this presumes that both are true perceptual effects. Another possibility is that both effects are due to response strategies, but feature priming encourages poor guessing. However, feature priming vanishes with a 500 -msec ISI, which discourages this interpretation. It is unlikely that subjects would adopt a strategy when $50 \mathrm{msec}$ separate primes and targets but would abandon it when the ISI reaches $500 \mathrm{msec}$. To clarify these issues, Goldinger et al. (1992) compared phonemic and feature priming, attempting to assess their respective bases. Toward this end, we juxtaposed each priming method, using a common pool of stimuli across experiments. Two aspects of method were particularly important. First, we assessed bias by comparing subjects' responses to unrelated trials across conditions. If priming in related trials creates a cost in unrelated trials, it implies a response strategy (den Heyer, Briand, \& Dannenbring, 1983; McLean \& Shulman, 1978; Posner \& Snyder, 1975). Second, phonemic and feature priming were compared across several procedural manipulations. If both effects come and go in tandem, it suggests a common underlying basis. But if they dissociate across manipulations, it suggests different bases.

The results were clear: In two identification experiments, the data suggested that different processes create phonemic and feature priming. First, when a $50 \%$ proportion of related priming trials was used, phonemic priming subjects systematically altered their responses to unrelated trials. Second, when a $10 \%$ proportion of related trials was used, phonemic priming was reduced, but fea- 
ture priming was unchanged. In three lexical decision experiments, we replicated the phonemic and feature priming effects (with degraded targets), and responses to unrelated trials again showed that phonemic priming entailed a bias. Also, phonemic priming stayed robust when the ISI increased to 500 or $1,500 \mathrm{msec}$, but feature priming vanished when the ISI exceeded $50 \mathrm{msec}$. Finally, reducing the proportion of related trials in phonemic priming actually reversed the effect, creating inhibition (as reported by Radeau et al., 1989; Radeau et al., 1995).

\section{Signal Detection Analyses of Priming Data}

The Goldinger et al. (1992) data suggest that phonemic and feature priming qualitatively differ. ${ }^{1}$ Feature priming seems to reflect transient lexical activation, but phonemic priming seems to reflect a response bias. More precisely, the phonemic priming data suggest an activation-based inhibition effect that is overturned by a facilitatory response bias. However, this conclusion is not completely satisfying. Feature priming seems to involve sensitivity changes without bias, but the evidence is indirect-we have not seen behaviors to indicate a bias. Similarly, phonemic priming does not seem to involve sensitivity changes (except, perhaps, in a negative direction), but the evidence is again indirect - we have not seen priming without also finding bias. More direct assessment of sensitivity and bias in both procedures is desirable. Toward that end, the present investigation compared phonemic and feature priming, using procedures that allow signal detection analyses (Green \& Swets, 1966).

In a study of visual word perception, Rhodes, Parkin, and Tremewan (1993) applied signal detection methods to semantic priming data, ostensibly separating sensitivity and bias components (see Farah, 1989). For example, Rhodes et al. presented masked word and nonword targets for lexical decision, after either semantically related or unrelated primes. In this task, sensitivity was increased by related primes, relative to control primes. Although this method seems appropriate, Norris (1995) raised two challenges. First, he showed that a pure bias model (which precluded sensitivity changes) could simulate Rhodes et al.'s (1993) data. By extension, this implies that sensitivity changes can be created by clever applications of bias. Moreover, Norris argued that word perception may violate a basic assumption of univariate signal detection theory - a singular criterion to discriminate between signal and noise distributions, broadly construed. In contrast, word perception theories assume a multidimensional space, wherein all words have their own thresholds (sensitivity) and idiosyncratic biases (Morton, 1969; Treisman, 1978). Words create singular perceptual experiences rather than sensations within the word distribution. As such, Norris argued that signal detection analyses of word perception may be misleading. The present study tested these suggestions.

The present experiments all involved forced-choice decisions about words in white noise (see Antos, 1979; Estes \& Brunn, 1987; Rhodes et al., 1993). Each target was half of a minimal word pair differing in initial phonemes, and each had associated phonemic, feature and unrelated primes. Related primes and targets were fully crossed, providing completely balanced designs. For example, two targets were ROPE and LOPE (a minimal pair differing in intial phonemes), which had the related primes ROB (which is phonetically related to LOPE and phonemically related to ROPE) and $\mathrm{LOB}$ (conversely related to each). The unrelated prime for both targets was MucH. The subjects received all possible priming combinations, although in different settings across experiments. To foreshadow the results, the concerns expressed by Norris (1995) were generally well conceived-signal detection theory does not easily apply to word perception. However, if a researcher can anticipate the likely form a bias will assume (in each trial), signal-detection methods remain useful in priming research.

\section{EXPERIMENT 1}

Experiment 1 was designed as a classic signal-detection task, allowing nonparametric estimation of sensitivity and bias. The method was one-interval forced-choice: On each trial, listeners heard a clear spoken prime, followed by an ISI and a degraded target. After the spoken target, a candidate response word was shown on the computer, flanked by boxes labeled yes and no. If the listener thought the target was indeed the word shown, yes was chosen via mouse click; otherwise no was chosen (correct response words were shown in half the trials). Subjects choosing yes correctly scored a hit, no correctly scored a correct rejection, yes incorrectly scored a false alarm (FA), and no incorrectly scored a miss. ${ }^{2}$

To complement the signal detection measures, two manipulations were used in Experiment 1. The first regarded block order. Half the subjects received a feature-priming block ( $50 \%$ feature primes; $50 \%$ unrelated primes), followed by a phonemic priming block $(50 \%$ phonemic primes, $50 \%$ unrelated primes). The other half received these blocks in reverse order. Across subjects, all possible combinations of primes, targets, and response options were presented equally often. Thus, each group had equal opportunity to generate hits and false alarms to all targets, following all primes. To clarify, Table 1 shows a representative stimulus set, and Table 2 shows all possible trials for each block.

Goldinger et al. (1992) hypothesized that phonemic priming subjects may learn the relevant prime-target relations and modify their behavior accordingly. We also hypothesized that feature priming, due to its subtlety, may not support effective learning. If we were correct, distinctive data patterns should emerge in Experiment 1,

Table 1

Example of a Stimulus Set, Experiment 1

\begin{tabular}{cccc}
\hline Targets & Feature Primes & Phonemic Primes & Unrelated Primes \\
\hline ROPE & LOB & ROB & MLCH \\
LOPE & ROB & LOB & MLCH \\
\hline
\end{tabular}


Table 2

Examples of All Possible Trials in Either Feature or Phonemic Priming Blocks, Experiment 1

\begin{tabular}{|c|c|c|c|}
\hline Prime & Target & Response Option & Correct Response \\
\hline \multicolumn{4}{|c|}{ Feature Priming Block } \\
\hline LOB & ROPE & ROPE? & $\mathrm{Y}(=$ hit; $\mathrm{N}=$ miss $)$ \\
\hline LOB & ROPE & LOPE? & $\mathrm{N}(=\mathrm{cr} ; \mathrm{Y}=\mathrm{fa})$ \\
\hline ROB & LOPE & LOPE? & $\mathrm{Y}(=$ hit $; \mathrm{N}=$ miss $)$ \\
\hline ROB & LOPE & ROPE? & $\mathrm{N}(=\mathrm{cr} ; \mathrm{Y}=\mathrm{fa})$ \\
\hline MUCH & ROPE & ROPE? & $\mathrm{Y}(=$ hit $; \mathrm{N}=$ miss $)$ \\
\hline $\mathrm{MUCH}$ & ROPE & LOPE? & $\mathrm{N}(=\mathrm{cr} ; \mathrm{Y}=\mathrm{fa})$ \\
\hline $\mathrm{MUCH}$ & LOPE & LOPE? & $\mathrm{Y}(=$ hit $; \mathrm{N}=$ miss $)$ \\
\hline $\mathrm{MUCH}$ & LOPE & ROPE? & $\mathrm{N}(=\mathrm{cr} ; \mathrm{Y}=\mathrm{fa})$ \\
\hline \multicolumn{4}{|c|}{ Phonemic Priming Block } \\
\hline LOB & LOPE & LOPE? & $Y(=$ hit; $N=$ miss $)$ \\
\hline LOB & LOPE & ROPE? & $\mathrm{N}(=\mathrm{cr} ; \mathrm{Y}=\mathrm{fa})$ \\
\hline ROB & ROPE & ROPE? & $\mathrm{Y}(=$ hit $; \mathrm{N}=$ miss $)$ \\
\hline ROB & ROPE & LOPE? & $N(=\mathrm{cr} ; Y=\mathrm{fa})$ \\
\hline MUCH & LOPE & LOPE? & $Y(=$ hit; $N=$ miss $)$ \\
\hline $\mathrm{MUCH}$ & LOPE & ROPE? & $\mathrm{N}(=\mathrm{cr} ; \mathrm{Y}=\mathrm{fa})$ \\
\hline $\mathrm{MUCH}$ & ROPE & ROPE? & $Y(=$ hit; $N=$ miss $)$ \\
\hline $\mathrm{MUCH}$ & ROPE & LOPE? & $\mathrm{N}(=\mathrm{cr} ; \mathrm{Y}=\mathrm{fa})$ \\
\hline
\end{tabular}

Notes-Y, yes; N, no; cr, correct rejection; fa, false alarm.

depending on block order. Those subjects who first receive feature priming should behave in a relatively pure manner. Specifically, their feature-priming data should resemble those observed by Goldinger et al. (1989; Goldinger et al., 1992).

On the other hand, those subjects who first receive phonemic priming should systematically alter their behavior. Specifically, a strategy learned in the phonemic block should carry over to the feature block, making the subjects reluctant to (correctly) answer yes to feature pairs (e.g., LOB-ROPE) that violate the previously learned phonemic pattern. Also, they should be predisposed to (incorrectly) answer yes to phonemic pairs (e.g., LOBLOPE) that follow the learned pattern. Thus, those subjects who first receive a phonemic block should generate fewer hits and more FAs in the subsequent feature block. No clear predictions arise for unrelated trials, which should act as a baseline.

The second manipulation in Experiment 1 involved the ISI between primes and targets. Goldinger et al. (1989; Goldinger et al., 1992) reported that feature priming is quite transient, vanishing when the ISI exceeds $50 \mathrm{msec}$, but phonemic priming is more robust. Separate groups in Experiment 1 received ISIs of 50 and $1,000 \mathrm{msec}$, respectively. (Goldinger et al. [1992], observed stable featureand phonemic priming patterns with ISIs of 500 and $1,500 \mathrm{msec}$. These values were averaged to the 1,000 msec ISI used presently.) If feature priming is sensitivity based and phonemic priming is bias based, the ISI manipulation should systematically affect feature priming, depending on block order. Specifically, in a featurefirst block, we expect no priming to occur with a long ISI. However, if the subjects develop a bias during phonemic blocks, feature-second subjects should exhibit priming across both ISIs.

\section{Method}

Subjects. One hundred sixty Arizona State University undergraduates participated for course credit. Eighty students participated in each ISI condition, with 40 students randomly assigned to each block order. In all the experiments reported here, all the subjects were native English speakers with no (self-reported) hearing disorders and with normal or corrected vision.

Stimuli. The stimulus materials were based on 96 minimal pairs of monosyllabic target words selected from a computer version of Webster's Seventh Collegiate Dictionary (1967). Once these targets were selected, phonemic and feature primes were selected for one member of each target pair. For the other member, the same primes were used, but their relationships to the target were reversed. For example, given the target pair ROPE-LOPE, the related primes were ROB and LOB; each prime is phonetically related to one target and phonemically related to the other. Finally, for each pair, one unrelated prime was chosen that bore no phonetic resemblance to either target. In the ROPE-LOPE example, the unrelated prime was MUCH. The entire 480-word stimulus set is listed in the Appendix

The feature primes were selected by searching the lexical database for each target's nearest neighbor with no common phonemes (Goldinger et al., 1989). Degrees of similarity between feature primes and targets were estimated via confusion matrices for all consonants and vowels at a $+5 \mathrm{~dB} \mathrm{~S} / \mathrm{N}$ ratio (see Luce, 1986, for a complete description). ${ }^{3}$ In most cases, phonemic primes were then generated merely by changing the intial phoneme of the feature prime to that of the target. This substitution occasionally created nonwords, so the nearest neighbor to the feature prime (with the desired initial phoneme) was selected from the database. The unrelated primes were selected from neighborhoods that were not phonetically confusable with the targets.

All the words were recorded on digital audiotape (spoken in isolation) in a sound-attenuated booth by a male speaker of midwestern dialect. Recordings were made with a Marantz PMD700 DAT recorder and a Beyer-Dynamic microphone. The words were lowpass filtered at $4.8 \mathrm{kHz}$ and were digitized at a $10-\mathrm{kHz}$ sampling rate, using a 12-bit analog-to-digital converter. All the words were excised from the digital list, using a waveform editor (CSRE) on a Gateway 2000 computer, and were stored for later use. To ensure intelligibility, 12 volunteers identified all words in the clear. Words that were not correctly identified by 10 listeners were replaced with better tokens. Finally, target words were digitally mixed with white noise at a constant $+5 \mathrm{~dB} S / \mathrm{N}$ ratio. To provide a counterbalanced design with no repeated words for any listener, the stimuli for feature and phonemic priming were arranged into eight lists, crossing all combinations of primes, targets, and response options. In each block order, 5 subjects received each list.

Procedure. The subjects were tested in groups of 8 or fewer in a quiet room. Each subject sat at a carrel equipped with a stand-alone PC clone and Sennheiser T 100 headphones. In each trial, a visual cue $\left({ }^{* *}\right)$ and a $500-\mathrm{Hz}$ tone were simultaneously presented for $200 \mathrm{msec}$, followed by a 300 -msec silent interval. A prime was then presented binaurally at approximately $70 \mathrm{~dB}$. Upon prime offset, the ISI (either 50 or $1,000 \mathrm{msec}$ ) elapsed, and a degraded target was presented. Five hundred milliseconds after target offset, a response word was shown (green, 24-point roman characters in a red box) in the center of the screen, flanked by yes and no boxes. The subject decided whether the spoken target matched the visual word, clicking the appropriate box with the left mouse key. Accuracy was stressed; RTs were recorded but were not emphasized. However, if a response was not entered in $5 \mathrm{sec}$, the computer initiated a new trial; 
Table 3

Mean Proportions of Hits and False Alarms as a Function of Block Order, Prime Type, and Interstimulus Interval (ISI) in Experiment 1

\begin{tabular}{ccc}
\hline & \multicolumn{2}{c}{ Block 1 } \\
\cline { 3 - 4 } ISI & $\frac{\text { Feature First }}{\text { Prime Type }}$ & Phonemic First \\
\cline { 2 - 4 } & Unrelated Feature & Unrelated Pype \\
\hline
\end{tabular}

50 -msec

\begin{tabular}{|c|c|c|c|c|}
\hline Hits & .81 & .64 & .80 & .91 \\
\hline FAs & .16 & .25 & .17 & .07 \\
\hline $000-\mathrm{m}$ & & & & \\
\hline Hits & .80 & .80 & .78 & .91 \\
\hline FAs & .19 & .25 & .19 & .11 \\
\hline & \multicolumn{4}{|c|}{ Block 2} \\
\hline & \multicolumn{2}{|c|}{ Feature First } & \multicolumn{2}{|c|}{ Phonemic First } \\
\hline & \multicolumn{2}{|c|}{ Prime Type } & \multicolumn{2}{|c|}{ Prime Type } \\
\hline & Unrelated & Phonemic & Unrelated & Feature \\
\hline
\end{tabular}

\begin{tabular}{lllll}
$50-\mathrm{msec}$ & & & & \\
Hits & .77 & .90 & .77 & .61 \\
FAs & .16 & .07 & .17 & .44 \\
l,000-msec & & & & \\
Hits & .78 & .93 & .80 & .66 \\
FAs & .19 & .09 & .18 & .39 \\
\hline
\end{tabular}

the aborted trial was repeated later in the session. The entire session (10 practice trials and 98 randomized test trials) lasted about $15 \mathrm{~min}$.

\section{Results and Discussion}

Hits. Mean hit and FA rates for all conditions (see Table 3 ) were analyzed in separate $2 \times 2 \times 2 \times 2$ (block order $\times$ block type $\times$ prime type $\times$ ISI) analyses of variance (ANOVAs). (Block type refers to feature vs. phonemic blocks; prime type refers to related vs. unrelated trials.) Several patterns were evident in the hit rates. Although the block order effect was unreliable (all statistical results assume a $p<.05$ criterion), it was involved in two reliable interactions: block order $\times$ block type $\left[F(1,155)=8.28, M S_{\mathrm{e}}=0.201\right]$ and block order $\times$ block type $\times$ prime type $\left[F(1,155)=6.90, M S_{\mathrm{e}}=0.215\right]$. Both interactions reflect a prominent cell of the design; feature primes yielded lower hit rates when subjects had already completed a phonemic block. Phonemic priming was unaffected by block order.

The block type effect (feature vs. phonemic) was robust $\left[F(1,155)=29.13, M S_{\mathrm{e}}=0.199\right]$, as was the block type $\times$ prime type interaction $\left[F(1,155)=70.02, M S_{\mathrm{e}}=\right.$ 0.199 ]. Both results reflect the opposite priming patterns in feature and phonemic blocks. Unrelated trials produced equivalent hits across prime types - feature and phonemic primes produced fewer and more hits, respectively, relative to this baseline. Given this pattern, the prime type effect was unreliable. The ISI effect was also unreliable, but a reliable block order $\times$ prime type $\times$ ISI interaction emerged $\left[F(2,155)=8.80, M S_{\mathrm{e}}=0.245\right]$. This reflected a difference in feature priming over ISIs, as a function of block order. Specifically, feature-first subjects replicated the Goldinger et al. (1989; Goldinger et al., 1992) data, showing feature priming only with a 50 -msec ISI. In contrast, feature-second subjects showed priming across both ISIs.

After the omnibus ANOVA, hit rates were tested for simple priming effects. With respect to feature priming, reliable inhibition was observed in the feature-first block with a 50 -msec ISI $\left[F(1,39)=13.52, M S_{\mathrm{e}}=4.77\right]$ and in the feature-second block at both the 50- and 1,000msec ISIs $\left[F(1,39)=41.90, M S_{\mathrm{e}}=6.04\right.$, and $F(1,39)=$ $18.01, M S_{\mathrm{e}}=7.19$, respectively]. Reliable phonemic priming was observed in all four cells: phonemic-first, 50 -msec ISI $\left[F(1,39)=11.95, M S_{\mathrm{e}}=3.01\right]$; phonemicfirst, 1,000-msec ISI $\left[F(1,39)=17.22, M S_{\mathrm{e}}=4.15\right]$; phonemic-second, 50-msec ISI $\left[F(1,39)=38.00, M S_{\mathrm{e}}=\right.$ 3.15]; and phonemic-second, $1,000-\mathrm{msec}$ ISI $[F(1,39)=$ $\left.27.98, M S_{\mathrm{e}}=3.04\right]$.

The hit rates generally followed their predicted pattern: Phonemic priming was unaffected by ISI and block order, but feature priming was comparatively malleable. When the feature-priming block was first, inhibition was evident at short ISIs. But when the phonemic priming block was first, subsequent feature priming was enhanced, becoming stable across ISIs. The obvious culprit is a bias learned during phonemic priming that carried over to the feature-priming block. A bias to respond "yes" when the visual word shares the prime's initial phoneme would increase hits in phonemic priming but would reduce hits in later feature priming. This account is corroborated by the false alarms.

False Alarms. As Table 3 shows, the FAs mirrored the hits-they were stable across block orders in phonemic priming but were malleable in feature priming. Indeed, the predicted effects were stronger in FAs than in hits, leading to a reliable block order effect $[F(1,155)=10.60$, $\left.M S_{\mathrm{e}}=2.95\right]$ and reliable interactions of block order $\times$ block type $\left[F(1,155)=8.02, M S_{\mathrm{e}}=2.95\right]$ and block order $\times$ prime type $\left[F(1,155)=9.16, M S_{\mathrm{e}}=2.95\right]$. A block type effect $\left[F(1,155)=19.21, M S_{\mathrm{e}}=4.02\right]$ and a block type $\times$ prime type interaction $[F(1,155)=83.30$, $\left.M S_{\mathrm{e}}=4.02\right]$ both reflected higher FAs in feature-priming trials. Indeed, all these results seem to reflect the inflated FAs to related, feature-second trials. No main effect or interactions involving ISI were reliable.

As with hit rates, the FAs were tested for simple priming effects. Despite the increased FAs to related trials in the feature-first block, no reliable priming was observed. In the feature-second block, however, robust priming (higher FAs to related trials) occurred at the 50- and 1,000msec ISIs $\left[F(1,39)=73.41, M S_{\mathrm{e}}=4.91\right.$, and $F(1,39)=$ $58.09, M S_{\mathrm{e}}=7.88$, respectively]. Reliable phonemic priming was observed in all four cells: phonemic-first, 50 -msec ISI $\left[F(1,39)=8.18, M S_{\mathrm{e}}=5.22\right] ;$ phonemicfirst, 1,000 -msec ISI $\left[F(1,39)=13.82, M S_{\mathrm{e}}=4.80\right]$; phonemic-second, 50-msec ISI $\left[F(1,39)=6.19, M S_{\mathrm{e}}=\right.$ 5.15]; and phonemic-second, 1,000-msec ISI $[F(1,39)=$ 9.03, $\left.M S_{\mathrm{e}}=5.70\right]$.

Signal detection analyses. Table 4 shows the derived estimates of $A^{\prime}$ and $B^{\prime \prime}$, calculated from hit and FA rates (Grier, 1971; Macmillan \& Creelman, 1990, 1991; Mc- 
Table 4

Mean $A^{\prime}$ and $B^{\prime \prime}$ Measures as a Function of Block Order, Prime Type, and Interstimulus Interval (ISI) in Experiment 1

\begin{tabular}{|c|c|c|c|c|}
\hline \multirow[b]{4}{*}{ ISI } & \multicolumn{4}{|c|}{ Block 1} \\
\hline & \multicolumn{2}{|c|}{ Feature First } & \multicolumn{2}{|c|}{ Phonemic First } \\
\hline & \multicolumn{2}{|c|}{ Prime Type } & \multicolumn{2}{|c|}{ Prime Type } \\
\hline & Unrelated & Feature & Unrelated & Phonemic \\
\hline \multicolumn{5}{|c|}{ 50-msec } \\
\hline$A^{\prime}$ & .89 & .78 & .89 & .96 \\
\hline$B^{\prime \prime}$ & .07 & .10 & .06 & .11 \\
\hline \multicolumn{5}{|c|}{1,000 -msec } \\
\hline$A^{\prime}$ & .88 & .86 & .87 & .94 \\
\hline \multirow[t]{4}{*}{$B^{\prime \prime}$} & .02 & -.08 & .05 & -.09 \\
\hline & \multicolumn{4}{|c|}{ Block 2} \\
\hline & \multicolumn{2}{|c|}{ Feature First } & \multicolumn{2}{|c|}{ Phonemic First } \\
\hline & \multicolumn{2}{|c|}{ Prime Type } & \multicolumn{2}{|c|}{ Prime Type } \\
\hline ISI & Unrelated & Phonemic & Unrelated & Feature \\
\hline \multicolumn{5}{|c|}{ 50-msec } \\
\hline$A^{\prime}$ & .88 & .95 & .88 & .64 \\
\hline$B^{\prime \prime}$ & .14 & .16 & .11 & -.02 \\
\hline \multicolumn{5}{|c|}{$1,000-\mathrm{msec}$} \\
\hline$A^{\prime}$ & .87 & .96 & .88 & .71 \\
\hline$B^{\prime \prime}$ & .05 & -.11 & .04 & -.03 \\
\hline
\end{tabular}

Nichol, 1972). $A^{\prime}$ is a nonparametric sensitivity measure (roughly analogous to $d^{\prime}$; Green \& Swets, 1966), representing the average of the minimum and maximum areas under the receiver-operating characteristic, as determined by hits and FAs. An $A^{\prime}$ equal to .5 denotes chance performance; 1.0 denotes perfect discrimination. $B^{\prime \prime}$ is a nonparametric bias measure, ranging from -1.0 to +1.0 . In the present experiment, a $B^{\prime \prime}$ of -1.0 denotes a complete bias to respond $n o$, and +1.0 denotes a complete bias to respond yes. Both measures are nonparametric because they do not require normality assumptions of the signal or noise distributions. However, if a bias exists in either direction, $A^{\prime}$ will underestimate sensitivity (McNichol, 1972). For this reason, both measures must be examined in tandem.

The $A^{\prime}$ and $B^{\prime \prime}$ analyses were generally less informative than direct examination of hits and FAs. In the $A^{\prime}$ data, the block order effect was null, but reliable interactions of block order $\times$ block type $\left[F(1,155)=10.09, M S_{\mathrm{e}}=\right.$ $0.012]$ and block order $\times$ block type $\times$ prime type $\left[F(1,155)=8.22, M S_{\mathrm{e}}=0.012\right]$ were observed. These interactions both reflect the lower mean sensitivity in the feature-second group. This also produced a reliable block type effect $\left[F(1,155)=11.82, M S_{\mathrm{e}}=0.023\right]$ and a block type $\times$ prime type interaction $\left[F(1,155)=31.94, M S_{\mathrm{e}}=\right.$ $0.023]$. No other $A^{\prime}$ results were significant. As is shown in Table 4, the $B^{\prime \prime}$ values were quite small, relative to their possible range. Indeed, no $B^{\prime \prime}$ results were statistically reliable.

Taken together, the Experiment 1 data present a mild paradox. On the one hand, the overall data pattern clearly reflects biased behavior. Feature priming created quite different results, depending on block order. When the subjects first completed a phonemic priming block, their hits decreased and FAs increased in the following feature block, relative to the feature blocks of reverse-order subjects. Another bias-indicative pattern was the longevity of priming effects across ISIs (Goldinger et al., 1992; McLean \& Shulman, 1978). Phonemic priming was consistent across ISIs, but feature priming was evident at the 1,000-msec ISI only for subjects who had already completed a phonemic priming block. On the other hand, the signal detection measures seemingly contradict a bias account - the pattern just described created reliable $A^{\prime}$ changes, without associated bias changes. That is, sensitivity in feature priming was reduced as a function of block order, which seems anomalous.

The explanation of these contrary data is clear, considering the unique form that a logical bias would assume in this task. As was noted by Norris (1995), signal detection theory assumes a unilateral criterion, such as a general bias to respond old in recognition memory. But in Experiment 1, a unilateral bias (favoring either yes or no) would make little sense, because each phonemic prime provides unique information for subjects to exploit. Specifically, they should learn that primes and targets often begin with the same sound. Thus, when a spoken target is not clearly understood, a logical bias would favor yes if the visual response word shares the prime's initial phoneme and would favor no otherwise. This strategy is globally consistent (as signal detection theory assumes), but locally dynamic - it can be flexibly applied to each trial. In phonemic trials, this flexible strategy would increase hits and decrease FAs, unlike a typical unilateral strategy (which would trade one against the other). And, if this phonemic strategy were applied in feature trials, it would decrease hits and increase FAs, as was observed. Naturally, a bias that changes both hits and FAs will affect the sensitivity measure, not the criterion. ${ }^{4}$

\section{EXPERIMENT 2}

The results of Experiment 1 were sensible, but it is rather unsatisfying to design a signal detection experiment, only to eventually belittle the measures it provides. Therefore, Experiment 2 was designed to improve the signal detection analyses from Experiment 1 and to allow direct assessment of the hypothesized flexible bias. The method was similar to that in Experiment 1, but unrelated-, feature-, and phonemic priming trials were intermixed (33\% each). However, the key change in Experiment 2 involved a preclassification of all trials. In a sense, the signal detection measures in Experiment 1 were destined to fail, because phonemic priming may promote both a bias and an antibias. That is, optimal subjects will shift their criteria bidirectionally across trials (as explained momentarily), creating an appearance of sensitivity increases without concomitant biases. In Experiment 2, all the trials were preclassified in such a manner as to better align with a logical, bidirectional bias.

Working from the hypothesis of the phonemic bias described above, several distinct classes of trials were pos- 
Table 5

Classification and Examples of Trial Types, Experiment 2

\begin{tabular}{|c|c|c|c|}
\hline Prime & Target & Response Option & Correct Response \\
\hline & & Control Hit/Miss & \\
\hline MUCH & LOPE & LOPE? & $\mathrm{Y}(=$ hit; $N=$ miss $)$ \\
\hline \multirow[t]{2}{*}{$\mathrm{MUCH}$} & ROPE & ROPE? & $\mathrm{Y}(=$ hit $; \mathrm{N}=$ miss $)$ \\
\hline & & Control FA/CR & \\
\hline MUCH & ROPE & LOPE? & $N(=c r ; Y=f a)$ \\
\hline \multirow[t]{2}{*}{$\mathrm{MUCH}$} & LOPE & ROPE? & $\mathrm{N}(=\mathrm{cr} ; \mathrm{Y}=\mathrm{fa})$ \\
\hline & & Biased Hit/Miss & \\
\hline LOB & LOPE & LOPE? & $\mathrm{Y}(=$ hit $; \mathrm{N}=$ miss $)$ \\
\hline \multirow[t]{2}{*}{ ROB } & ROPE & ROPE? & $\mathrm{Y}(=$ hit; $\mathrm{N}=$ miss $)$ \\
\hline & & Biased FA/CR & \\
\hline LOB & ROPE & LOPE? & $\mathrm{N}(=\mathrm{cr} ; \mathrm{Y}=\mathrm{fa})$ \\
\hline \multirow[t]{2}{*}{ ROB } & LOPE & ROPE? & $\mathrm{N}(=\mathrm{cr} ; \mathrm{Y}=\mathrm{fa})$ \\
\hline & & Antibiased Hit/Miss & \\
\hline LOB & ROPE & ROPE? & $\mathrm{Y}(=$ hit $; \mathrm{N}=$ miss $)$ \\
\hline \multirow[t]{2}{*}{ ROB } & LOPE & LOPE? & $\mathrm{Y}(=$ hit $; \mathrm{N}=$ miss $)$ \\
\hline & & Antibiased FA/CR & \\
\hline LOB & LOPE & ROPE? & $\mathrm{N}(=\mathrm{cr} ; \mathrm{Y}=\mathrm{fa})$ \\
\hline ROB & ROPE & LOPE? & $\mathrm{N}(=\mathrm{cr} ; \mathrm{Y}=\mathrm{fa})$ \\
\hline
\end{tabular}

Note - $Y$, yes; $N$, no; $c r$, correct rejection; fa, false alarm.

sible in Experiment 2. These are summarized (with examples) in Table 5. Assuming a subject answers "yes," unrelated priming trials will generate control hit and FA rates, as the bias should rarely be applied. Depending on the visual response option provided, phonemic priming trials will generate either biased hits or antibiased FAs. Biased hits will occur when the correct option is shown (e.g., LOB-LOPE; LOPE?), as a phonemically biased subject would be inclined to correctly respond "yes," regardless of the target's perceptual clarity. Antibiased FAs will occur when the incorrect option is shown (e.g., LOBLOPE; ROPE?), as a biased subject would be inclined to correctly respond "no," regardless of perceptual clarity.

In a symmetric manner, feature-priming trials will generate either biased FAs or antibiased hits, depending upon the response option shown. Biased FAs will occur when the incorrect option is shown (e.g., LOB- ROPE; LOPE?), as a phonology-biased subject will be inclined to incorrectly respond "yes," regardless of the target's perceptual clarity. Antibiased hits will occur when the correct option is shown (e.g., LOB-ROPE; ROPE?), as a biased subject would be inclined to incorrectly respond "no," regardless of the target's perceptual clarity. Thus, by juxtaposing the feature- and phonemic priming relations (with controls) in a single context and by predicting the likely form of a trial-specific bias, we can separately examine biased and antibiased trials, allowing more meaningful signal detection analyses for each. This method was applied in Experiment 2, again examining ISIs of 50 and $1,000 \mathrm{msec}$.

To determine the likely effects of Experiment 2, a post hoc analysis was conducted on half the Experiment 1 data. Specifically, the data from phonemic-first subjects were realigned, creating control, biased, and antibiased trials, as described in Table 5. Because ISI had no effect in these conditions of Experiment 1, the 50- and 1,000msec ISI data were averaged. The results were quite different from those shown in Table 4: Control trials $\left(A^{\prime}=\right.$ $.8539 ; B^{\prime \prime}=.0202$ ) displayed virtually no bias; biased trials $\left(A^{\prime}=.8301 ; B^{\prime \prime}=-.4005\right)$ displayed a clear negative bias; and antibiased trials $\left(A^{\prime}=.8499 ; B^{\prime \prime}=.3850\right)$ displayed a clear positive bias. This post hoc analysis confirms that bidirectional biases affected Experiment 1. It also suggests that similar results should arise in Experiment 2 , which provided a better test by presenting all trials in a truly random order.

\section{Method}

Subjects. One hundred forty-four Arizona State University undergraduates participated for course credit, with 72 students in each ISI condition.

Stimuli. The stimuli from Experiment 1 were used in Experiment 2 but were organized into 12 new counterbalanced lists, ensuring that all possible combinations of primes, targets, and responses were equally represented across subjects. At each ISI, these 12 lists were each presented to 6 subjects.

Procedure. The procedures were identical to those of Experiment 1 , except that all trials were presented in a single, randomized block.

\section{Results and Discussion}

Mean hit and FA rates were calculated for each trial type (control, biased, and antibiased) at each ISI. These are shown in Table 6 , along with derived $A^{\prime}$ and $B^{\prime \prime}$ estimates. These data were analyzed in separate $3 \times 2$ (trial type $\times$ ISI) ANOVAs. Unlike Experiment 1 , all dependent measures in Experiment 2 generated similar results.

Hits. As Table 6 shows, hit rates were high in biased trials and were low in antibiased trials, each relative to control trials. The trial type effect was reliable $[F(2,141)=$ $\left.121.07, M S_{\mathrm{e}}=0.112\right]$, as were both simple comparisons: Biased trials generated more hits $[F(1,143)=44.61$, $\left.M S_{\mathrm{e}}=0.220\right]$ and antibiased trials generated fewer hits than did control trials $\left[F(1,143)=82.53, M S_{\mathrm{e}}=0.193\right]$. The ISI effect was null, but the trial type $\times$ ISI interaction was reliable $\left[F(2,141)=9.89, M S_{\mathrm{e}}=0.112\right]$. This occurred because hits increased across ISIs in biased trials $\left[F(1,71)=24.19, M S_{\mathrm{e}}=0.311\right]$ and decreased across ISIs in antibiased trials $\left[F(1,71)=37.00, M S_{\mathrm{e}}=0.402\right]$.

\section{Table 6}

Mean Proportions of Hits and False Alarms and Mean $\boldsymbol{A}^{\prime}$ and $\boldsymbol{B}^{\prime \prime}$ Estimates in Experiment 2

\begin{tabular}{ccccc}
\hline Trial Type & Hit Rate & False Alarm Rate & $A^{\prime}$ & $B^{\prime \prime}$ \\
\hline Control & (M-L-L?) & (M-L-R?) & & \\
50 -msec ISI & .78 & .19 & .88 & .04 \\
1,000-msec ISI & .81 & .18 & .89 & .02 \\
Biased & (L-L-L?) & (L-R-L?) & & \\
50 -msec ISI & .85 & .27 & .86 & -.21 \\
$1,000-$ msec ISI & .94 & .53 & .83 & -.63 \\
Anti-Biased & (L-R-R?) & (L-L-R?) & & \\
50-msec ISI & .67 & .11 & .87 & .39 \\
1,000-msec ISI & .59 & .06 & .87 & .62 \\
\hline
\end{tabular}

Note--Parenthesized letters refer to example sequences (see Table 5). 
False Alarms. As Table 6 also shows, the FAs generally followed the hits, creating a reliable trial type effect $\left[F(2,141)=422.79, M S_{\mathrm{e}}=0.025\right]$. As in the hit rates, biased trials generated more FAs $[F(1,143)=204.11$, $\left.M S_{\mathrm{e}}=0.076\right]$, and antibiased trials generated fewer FAs than did control trials $\left[F(1,143)=47.88, M S_{\mathrm{e}}=0.081\right]$. The ISI effect was null, but the trial type $\times$ ISI interaction was reliable $\left[F(2,141)=30.37, M S_{\mathrm{e}}=0.025\right]$, again because FAs increased across ISIs in biased trials $\left[F(1,71)=50.86, M S_{\mathrm{e}}=0.084\right]$ and slightly decreased across ISIs in antibiased trials.

Sensitivity $\left(\boldsymbol{A}^{\prime}\right)$. As in Experiment 1, hits and FAs compensated for each other in Experiment 2. Thus, the $A^{\prime}$ analysis only revealed two simple effects: Sensitivity was lower in biased trials than in control trials $[F(1,143)=$ $15.20, M S_{\mathrm{e}}=0.144$ ], and sensitivity in biased trials was reduced across ISIs $\left[F(1,143)=8.19, M S_{\mathrm{e}}=0.175\right]$.

Bias $\left(B^{\prime \prime}\right)$. Unlike Experiment 1, the $B^{\prime \prime}$ analyses revealed clear patterns in Experiment 2. A robust trial type effect $\left[F(2,141)=215.81, M S_{\mathrm{e}}=0.298\right]$ reflected two simple effects: $B^{\prime \prime}$ was strongly negative in biased trials $\left[F(1,143)=97.83, M S_{\mathrm{e}}=0.303\right]$ and was strongly positive in antibiased trials, each relative to control trials $\left[F(1,143)=75.14, M S_{\mathrm{e}}=0.384\right]$. The ISI effect was unreliable, but a trial type $\times$ ISI interaction $[F(2,141)=$ $\left.159.66, M S_{\mathrm{e}}=0.298\right]$ also reflected opposite simple effects: $B^{\prime \prime}$ decreased across ISIs in biased trials $[F(1,71)=$ 23.05, $\left.M S_{\mathrm{e}}=0.191\right]$ and increased across ISIs in antibiased trials $\left[F(1,71)=17.40, M S_{\mathrm{e}}=0.202\right]$. Each simple effect reflected stronger biases at the longer ISI.

\section{EXPERIMENT 3}

Experiment 2 complemented Experiment 1, verifying the hypothesized, bidirectional phonemic bias. When the experimental trials are properly contrasted with respect to this bias, the signal detection measures more closely align with observed hits and FAs. The data therefore suggest that, if one can anticipate the likely form a bias will assume (as in phonemic priming), signal detection analyses can be applied to multidimensional stimuli. Unfortunately, although the $B$ " indices in Experiment 2 clearly revealed a bias, the sensitivity question remains. As noted earlier, given a bias in either direction, $A^{\prime}$ will underestimate sensitivity (McNichol, 1972). Experiment 3 was conducted to further examine sensitivity, using a twoalternative forced-choice ( $2 \mathrm{AFC}$ ) method. The prior materials were used, but the response options were changed. Instead of showing one word for a yes-no decision, two words were shown for forced-choice identification. For example, a subject might hear $\mathrm{LOB}-\mathrm{ROPE}$, followed by the visual response options ROPE and LOPE. As in Experiment 2, unrelated-, phonemic-, and feature-priming trials were combined in a single block ( $33 \%$ each), but different groups now received a 50 - or 1,000-msec ISI.

To assess sensitivity changes in semantic priming, Rhodes et al. (1993) also conducted a 2AFC experiment. In univariate signal detection theory, percent correct in
2AFC is a sensitivity index that is unaffected by criterion bias (Macmillan \& Creelman, 1990, 1991; Sekuler \& Blake, 1990). However, Norris (1995) fit a pure-bias model to the Rhodes et al. 2AFC data, producing tight qualitative fits. Given this contradiction, Experiment 3 examined the same basic issues as Experiments 1 and 2: First, can we find evidence of a true phonemic priming effect? Second, is the $2 \mathrm{AFC}$ procedure really bias free when words are used as experimental stimuli?

\section{Method}

Subjects. Ninety-six Arizona State University undergraduates participated for course credit, with 48 students in each ISI condition.

Stimuli. The stimuli were identical to those of Experiment 2. However, given the $2 \mathrm{AFC}$ procedure, response options no longer required counterbalancing. Thus, only six stimulus lists were required; each list was tested at each ISI with 8 subjects.

Procedure. The Experiment 3 procedures were identical to those of Experiment 2, except that both members of the minimal target pair were shown (side by side) on every trial. Correct responses were randomly but equally mapped to the left and right.

\section{Results and Discussion}

Mean percentages of correct classification for each kind of priming trial (see Table 7) were analyzed in a 3 $\times 2$ (trial type $\times$ ISI) ANOVA. A reliable trial type effect was observed $\left[F(2,93)=9.67, M S_{\mathrm{e}}=0.103\right]$. Although feature trials were less accurate than unrelated trials, the difference was not reliable. However, phonemic trials were reliably more accurate than unrelated trials $\left[F(1,94)=18.90, M S_{\mathrm{e}}=0.138\right]$. Among simple effects, feature priming created reliable inhibition at the 50 -msec ISI $\left[F(2,46)=30.02, M S_{\mathrm{e}}=0.299\right]$ and phonemic priming created reliable facilitation at both ISIs [50-msec: $F(2,46)=25.24, M S_{\mathrm{e}}=0.317 ; 1,000$-msec: $F(2,46)=$ $\left.19.58, M S_{\mathrm{e}}=0.405\right]$. The ISI effect was null, but a trial type $\times$ ISI interaction $\left[F(2,93)=7.44, M S_{\mathrm{e}}=0.103\right] \mathrm{re}-$ flected the singular sensitivity of feature priming to the ISI manipulation $\left[F(1,94)=22.08, M S_{\mathrm{e}}=0.161\right]$.

Despite the 2AFC method, the proper interpretation of Experiment 3 is unclear. In general, the data replicated those of Goldinger et al. (1992): Feature and phonemic priming each occurred with a 50 -msec ISI; only phonemic priming remained with a $1,000-\mathrm{msec}$ ISI. However, we previously considered robust phonemic priming with a long ISI indicative of a bias (McLean \& Shulman, 1978; Neely, 1991). Thus, how should the phonemic priming in Experiment 3 be interpreted? Do the 50-msec ISI data implicate sensitivity? Do the $1,000-\mathrm{msec}$ ISI data implicate bias?

This problem of interpretation is reminiscent of Experiment 1 and was anticipated by Norris (1995). Specif-

Table 7

Mean Percent Correct in Two-Alternative Forced-Choice Classification in Experiment 3

ISI Unrelated Priming Feature Priming Phonemic Priming

\begin{tabular}{llll}
\hline $50-\mathrm{msec}$ & 75.1 & 66.2 & 84.4 \\
$1,000-\mathrm{msec}$ & 75.9 & 77.0 & 85.6 \\
\hline
\end{tabular}


ically, an optimal strategy in Experiment 3 would be flexible (albeit consistent) across trials. Subjects should quickly learn that primes and targets occasionally share initial phonemes. Given two alternatives, a wise strategy is to select whichever word shares the prime's intial phoneme. In other words, the assumption that $2 \mathrm{AFC}$ provides a bias-free sensitivity estimate may only apply to standard signal detection paradigms. When a procedure allows trial-by-trial optimization, bias effects may be more insidious, even affecting $2 \mathrm{AFC}$ data. Alternatively, perhaps no biases were involved in Experiment 3-phonemic priming may survive longer ISIs because the relevant sublexical structures are more completely activated, relative to feature priming. These hypotheses were tested in Experiment 4.

\section{EXPERIMENT 4}

Experiment 3 was intended to estimate priming-based sensitivity changes, independent of biases. However, a flexible, trial-specific bias remained possible. Moreover, the forced-choice procedure precludes a reclassification of trials, as in Experiment 2. Given the elusive nature of such a bias, indirect measures are most likely to reveal it. Such an indirect method was applied in Experiment 1, as a block order manipulation that created inappropriate carryover effects (Becker, 1980). In Experiment 4, the method from Goldinger et al. (1992) was applied, allowing unrelated trials to help reveal a bias. Experiment 4 used a four-alternative forced-choice (4AFC) procedure, in which the two extra choices on each trial were catch foils, designed to reflect specific biases.

To return to a familiar example, consider the following stimulus set:

$\begin{array}{ccc} & \text { Feature and } & \\ \text { Targets } & \text { Phonemic Primes } & \text { Unrelated Primes } \\ \text { ROPE-LOPE } & \text { LOB-ROB } & \text { MUCH }\end{array}$

In Experiment 3 (2AFC), the response choices ROPE and LOPE were shown in any trial involving this stimulus set. Thus, given the prime LOB or ROB, a phonemically motivated response option was provided, but neither response could verify a possible bias. And, given the prime $\mathrm{MUCH}$, either response was equally indicated, providing a baseline. In Experiment 4 (4AFC), the unrelated trials were more informative. Now, in addition to ROPE and LOPE, the response choices MOPE and NOPE were shown.

The extra choices MOPE and NOPE constitute catch foils, because they are each potentially related to the unrelated prime MUCH. If a subject develops either a phonemic or a feature bias, $\mathrm{MUCH}$ may induce erroneous selection of MOPE or NOPE, respectively. (Naturally, given their acoustic dissimilarity to the targets, catch foils should be chosen quite infrequently, even if subjects are biased.) Thus, every trial presented a correct response, a target foil (an acoustic neighbor to the real target), a phonemic foil (to detect a phonemic bias), and a feature foil (to detect a phonetic bias). Experiment 4 was a conceptual replication of
Table 8

Percent Correct in Four-Alternative Forced-Choice Classification and Percentages of Foil Selections in Experiment 4

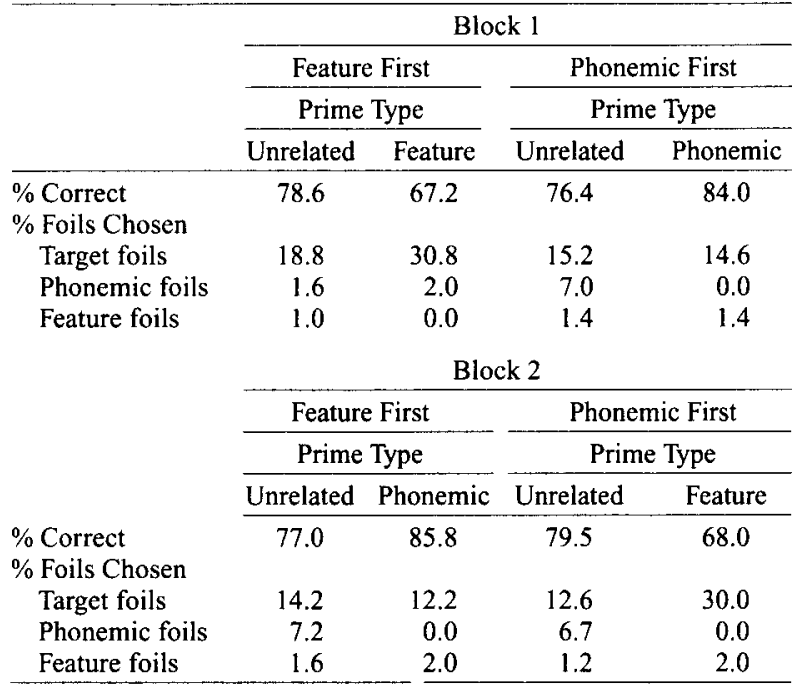

Experiment 1, testing feature and phonemic priming in separate, ordered blocks. However, only a 50 -msec ISI was used (in Experiment 1, feature priming only occurred with a short ISI).

\section{Method}

Subjects. Eighty Arizona State University undergraduates participated in Experiment 4 for course credit.

Stimuli. The stimuli were identical to those of the previous experiments, except for the additional catch foils, shown in the Appendix

Procedure. Within-trial procedures were identical to those of Experiment 3, but four response options were shown on every trial, and only a 50-msec ISI was used. Response options were shown side by side; correct responses were randomly but equally mapped to all positions. The subjects completed separate blocks, one with unrelated and feature primes ( $50 \%$ each), and one with unrelated and phonemic primes. Half completed the feature block first, and half completed the phonemic block first.

\section{Results and Discussion}

Correct classifications. The mean percentages of correct classification (see Table 8 ) were analyzed in a $2 \times 2 \times 2$ ANOVA examining block order, block type, and prime type. Main effects of block order and prime type were both unreliable, but the block type effect was significant $\left[F(1,77)=8.18, M S_{\mathrm{e}}=6.30\right]$. This reflected a difference in feature and phonemic priming accuracy, as verified by a block type $\times$ prime type interaction $\left[F(1,77)=44.13, M S_{\mathrm{e}}=6.30\right]$. No other interactions were reliable.

The data of primary interest were responses to different foils (Table 8 ), which were analyzed in a $3 \times 2 \times 2$ $\times 2$ ANOVA in which foil type, block order, block type, and prime type were examined. The main effect of foil type was robust $\left[F(2,76)=131.09, M S_{\mathrm{e}}=2.92\right]$, reflecting high error rates to target foils, relative to feature and phonemic foils. The main effects of block order, 
block type, and prime type were all null. However, three key interactions emerged. A foil type $\times$ prime type interaction $\left[F(2,76)=51.90, M S_{\mathrm{e}}=2.92\right]$ reflected the higher incidence of phonemic foils selected after unrelated primes. A foil type $\times$ block type interaction $[F(2,76)=$ $\left.34.18, M S_{\mathrm{e}}=2.92\right]$ isolated this trend to the phonemic priming blocks, and a foil type $\times$ block type $\times$ block order interaction $\left[F(2,76)=16.78, M S_{\mathrm{e}}=2.92\right]$ reflected the inflated phonemic foil selections in the feature-second block. A planned comparison confirmed that phonemic foils were selected more often than feature foils $[F(1,79)$ $\left.=102.55, M S_{\mathrm{e}}=0.97\right]$. However, a predicted pattern emerged -in block 1, feature-priming subjects selected few phonemic foils, relative to phonemic priming subjects $\left[F(2,76)=131.09, M S_{\mathrm{e}}=2.92\right]$. In block 2, this difference vanished.

The Experiment 4 results were reminiscent of Experiments 1 and 2. Specifically, a bias generated in phonemic priming was evident in two regards. First, the subjects were most likely to select phonemic foils (e.g., MUCHROPE leading to selection of MOPE) in the context of a phonemic priming block. No symmetric bias toward feature foils was observed in feature-priming blocks. Second, the subjects who first received a phonemic priming block (and thereby had opportunity to develop a bias) were more likely to select phonemic foils in the subsequent feature-priming block, relative to subjects who completed the feature-priming block first. Together, the data suggest that subjects can easily develop a phonemic bias but do not develop a feature bias. Moreover, they show that forced-choice procedures are not bias free when lexical stimuli are used.

\section{GENERAL DISCUSSION}

This investigation was motivated by a deceptively simple idea. The phonemic priming effect (Slowiaczek et al., 1987) is an important finding, potentially revealing the dynamics of spoken word perception. However, the effect has not inspired great confidence, being ephemeral across tasks (Radeau et al., 1989; Radeau et al., 1995; Slowiaczek \& Pisoni, 1986) and showing associated response biases (Goldinger et al., 1992). The present experiments were conducted to provide signal detection measures of form-based priming effects. Presumably, once the veneer of bias is removed, true priming can be examined, as Rhodes et al. (1993) attempted with semantic priming. Unfortunately, Norris (1995) showed that the Rhodes et al. data were equivocal with respect to underlying mechanisms. Despite using comparatively simple prime-target relations, the present signal detection tests also proved quite challenging. Indeed, in all experiments (including forced-choice tests purported to provide bias-free sensitivity estimates), biases hindered the interpretation of priming effects.

Following Goldinger et al. (1992), the present study juxtaposed phonemic and feature priming because both effects are easily created in a common experiment, they typically have opposite directions of effect, and they dissociate across procedural changes. Goldinger et al. (1992) found that phonemic priming generated biases, but feature priming did not (presumably due to subtle prime-target relations). In Experiment 1, the hit and FA rates showed both priming and bias effects, but the signal detection measures did not. This pattern suggested the possibility of a flexible, trial-specific bias. Experiment 2 confirmed this bias effect by preclassifying trials in a manner consistent with a logical bias. Feature and phonemic priming were also observed in a "bias-free" 2 AFC test (Experiment 3). However, considering the trial-specific form of a likely phonemic bias, it still seemed that subjects could optimize responding. Experiment 4 used a 4 AFC procedure, directly showing that phonemic priming and bias go hand-in-hand.

The key finding in this study was an insidious, flexible bias in phonemic priming. In classic signal detection theory, the criterion setting is monolithic. For example, an observer may be generally conservative in recognition memory, saying "no" in response to any uncertainty. However, such a unilateral bias would be counterproductive in phonemic priming. Instead, the best strategy is to note each prime's initial phoneme and to make target responses contingent on its repetition. In this manner, performance can be optimized, improving both hit and FA rates in related priming trials. Formally, this is a sensitivity change. But intuitively, it is a bias. Taken together with observations from Norris (1995), this pattern raises two questions: Could phonemic priming plausibly be explained by sensitivity changes (in theory)? If so, could it be empirically established? Both answers seem to be "yes."

With respect to the first question, various theories of spoken word perception predict phonemic priming, without any strategy assumptions (e.g., McClelland \& Elman, 1986). Given their shared phonemes, primes should preactivate targets (either at lexical or sublexical levels), leading to improved target perception. By almost any account, this is a sensitivity-based priming effect. Indeed, such activation-based priming may have contributed to effects in the present study. However, if a true phonemic priming effect exists in the data, it cannot be distinguished from its concomitant response bias.

With respect to the second question, the present methods can reveal either sensitivity or bias effects, but they cannot provide truly separate indices. For example, if phonemic priming simply improved target perception, hit and FA rates would benefit, without affecting other aspects of the data. But in the present study, phonemic priming consistently affected responses to later featurepriming blocks - a clear bias signature. By contrast, feature priming seemed to create true sensitivity changes, without any observable bias. By directly testing for bias effects, the present methods entail a strong standard of evidence: True priming effects require sensitivity changes in related priming trials, without unexplained changes in other trials. Given the present data, we cannot conclude that phonemic priming is absent, but we know that phonemic bias is present. 


\section{Alternative Methods for Examining Priming}

Admittedly, this study likely encouraged bias, relative to other priming studies, by using degraded words and emphasizing accuracy. It is somewhat ironic that the entailments of signal detection research may promote bias, as its major advantage is the ability to decouple sensitivity from bias. In any case, the results show that priming data should not be considered a clear window on perceptual processes, even when signal detection methods are used (Norris, 1995). A natural question thus arises: Could other priming methods provide cleaner data? This has been previously considered in phonemic priming, but more extensively with respect to semantic priming (Becker, 1980; Ratcliff, McKoon, \& Verwoerd, 1989; Seidenberg, Waters, Sanders, \& Langer, 1984).

Given the likelihood of biases when degraded words are used, the best alternatives are RT paradigms entailing clear words and few postaccess processes. Indeed, this progression has characterized the brief history of phonemic priming research. Slowiaczek et al. (1987) observed robust priming when listeners identified words in noise. Concerned about guessing strategies, Slowiaczek and Pisoni (1986) repeated the experiments with lexical decision. Although lexical decision involves postaccess processes (Balota \& Chumbley, 1984), it is likely that it involves less deliberation than does perceptual identification. Unfortunately, phonemic priming either failed to replicate in lexical decision or showed a bias component (Goldinger et al., 1992). To further reduce biases, researchers have turned to the shadowing task (Hamburger \& Slowiaczek, 1996; Radeau et al., 1989). However, biases may also affect shadowing data. In a study of primed visual word naming, Keefe and Neely (1990) observed strong bias effects, indicated by sensitivity to changing proportions of related trials. They concluded that:

in order to account for priming effects in pronunciation, one cannot ignore that subjects will use a prime to generate an expectancy set containing items related to that prime when it is advantageous for them to do so. (p. 297)

Given such results in visual word naming, it seems likely that spoken word shadowing would also involve biases. Indeed, Hamburger and Slowiaczek (1996) found an apparent bias in their one-phoneme overlap trials, and Goldinger (in press) found clear biases in primed shadowing. The implication is clear: Even a seemingly shallow priming task can involve extensive processing and thus requires cautious interpretation. Indeed, copious semantic priming research suggests that all priming effects require cautious interpretation (Becker, 1980; den Heyer et al., 1983; Posner \& Snyder, 1975; Ratcliff et al., 1989).

Similar difficulties arise in both phonemic and semantic priming - both entail a confound of the automatic and controlled components of behavior (Neely, 1977, 1991). Despite reports (Farah, 1989; Rhodes et al., 1993), the present data suggest that signal detection methods may not allow separate assessment of these components. However, alternative methods are available. To address the bias problem, an ideal experiment either will remove one behavioral component or will remove the confound by setting the components to orthogonal tasks. More concretely, either the subject must be unaware of the priming relationship under test (as feature priming seems to accomplish), or the subject's learned and natural responses to the priming relationship must be placed in mutual opposition. Both approaches have been used in semantic priming research and may be applied to form-based priming.

With respect to the first approach, making subjects unaware of prime-target relationships can be challenging. Thus, some investigators have made subjects unaware of the primes entirely via subliminal presentation (Holender, 1986). This method has been used in semantic priming of printed words (Balota, 1983; Fischler, 1977; Fowler, Wolford, Slade, \& Tassinary, 1981; Hines, Czerwinski, Sawyer, \& Dwyer, 1986; Marcel, 1983) and to study visual form priming (Forster, 1987; Forster \& Davis, 1991; Forster \& Taft, 1994). Of course, these methods require precautions (Cheesman \& Merikle, 1984) and may not generalize to auditory primes.

The second approach-setting the behavioral components of priming to cross-purposes - may hold more promise for application to phonemic priming. Neely (1977; Favreau \& Segalowitz, 1983) introduced a semantic priming method in which activation (Collins \& Loftus, 1975) and bias are separated via instructions to subjects. Neely presented natural associates (e.g., BIRD- ROBIN) as primes and targets, separated by varying ISIs. For some category names (e.g., BODY), subjects were advised that targets would belong to a different natural category (e.g., building parts). The instructions usually held true, so subjects seeing the prime BODY learned to expect building words as targets. However, natural associates (e.g., ARM) were occasionally shown instead. Neely found independent effects of each hypothesized component of priming. At short ISIs, despite instructions, subjects showed facilitated processing of natural targets (e.g., BODY-ARM). But at longer ISIs, this normal priming was reversed; RTs followed the prescribed bias rather than real conceptual relations. ${ }^{5}$

In general, researchers are interested in the automatic aspects of priming, which may reveal the connectivity of lexical items, cooperative-competitive dynamics, and so forth. Biases are typically considered noise in the data. However, the flexible-bias problem may be unavoidable in priming, presuming that subjects try to optimize their behavior (Keefe \& Neely, 1990). A recent trend is to use shallow processing tasks (e.g., shadowing) and to interpret the data relatively uncritically. A safer method is to allow biases to exert a predictable and separable effect on the data. Once biases are identified, theoretically relevant priming effects may be examined.

\section{REFERENCES}

Antos, S. (1979). Processing facilitation in a lexical decision task. Journal of Experimental Psychology: Human Perception \& Performance, 5, 527-545.

BAlota, D. A. (1983). Automatic semantic activation and episodic 
memory encoding. Journal of Verbal Learning \& Verbal Behavior, 22, 88-104.

Balota, D. A., \& Chumbley, J. I. (1984). Are lexical decisions a good measure of lexical access? The role of word frequency in the neglected decision stage. Journal of Experimental Psychology: Human Perception \& Performance, 10, 340-357.

BECKER, C. A. (1980). Semantic context effects in visual word recognition: An analysis of semantic strategies. Memory \& Cognition, 8, 493-512.

Cheesman, J., \& Merikle, P. M. (1984). Priming with and without awareness. Perception \& Psychophysics, 36, 387-395.

Collins, A., \& LofTUs, E. (1975). A spreading activation theory of semantic processing. Psychological Review, 82, 407-428.

DEN Heyer, K., Briand, K., \& Dannengring, G. L. (1983). Strategic factors in a lexical-decision task: Evidence for automatic and attentiondriven processes. Memory \& Cognition, 11, 374-381.

Estes, W. K., \& BRUNn, J. L. (1987). Discriminability and bias in the word-superiority effect. Perception \& Psychophysics, 42, 411-422.

FARAH, M. (1989). Semantic and perceptual priming: How similar are the underlying mechanisms? Journal of Experimental Psychology: Human Perception \& Performance, 15, 188-194.

Favreau, M., \& Segalowitz, N. S. (1983). Automatic and controlled processes in the first- and second-language reading of fluent bilinguals. Memory \& Cognition, 11, 565-574.

FISCHLER, I. (1977). Associative facilitation without expectancy in a lexical decision task. Journal of Experimental Psychology: Human Perception \& Performance, 3, 18-26.

ForSTER, K. I. (1987). Form-priming with masked primes: The best match hypothesis. In M. Coltheart (Ed.), Attention and performance XII (pp. 127-146). London: Erlbaum.

Forster, K. I., \& DAVIS, C. (1991). The density constraint on formpriming in the naming task: Interference effects from a masked prime. Journal of Memory \& Language, 30, 1-25.

FoRSTER, K. I., \& TAFT, M. (1994). Bodies, antibodies, and neighborhooddensity effects in masked form-priming. Journal of Experimental Psychology: Learning, Memory, \& Cognition, 20, 844-863.

Fowler, C. A., Wolford, G., Slade, R., \& TASSinary, L. (1981). Lexical access with and without awareness. Journal of Experimental Psychology: General, 110, 341-362.

GOLDINGER, S. D. (in press). Only the shadower knows: Comment on Hamburger and Slowiaczek (1996). Psychonomic Bulletin \& Review.

Goldinger, S. D., LuCE, P. A., \& Pisoni, D. B. (1989). Priming lexical neighbors of spoken words: Effects of competition and inhibition. Journal of Memory \& Language, 28, 501-518.

Goldinger, S. D., Luce, P. A., Pisoni, D. B., \& Marcario, J. K. (1992). Form-based priming in spoken word recognition: The roles of competition and bias. Journal of Experimental Psychology: Learning, Memory, \& Cognition, 18, 1211-1238.

GREEN, D. M., \& SwETS, J. A. (1966). Signal detection theory and psychophysics. New York: Wiley.

GRIER, J. B. (1971). Nonparametric indexes for sensitivity and bias: Computing formulas. Psychological Bulletin, 75, 424-429.

Hamburger, M., \& Slowiaczek, L. M. (1996). Phonological priming reflects lexical competition. Psychonomic Bulletin \& Review, 3, 520-525.

Hines, D., Czerwinski, M., SAWyer, P. K., \& DWyer, M. (1986). Automatic semantic priming: Effect of category exemplar level and word association level. Journal of Experimental Psychology: Human Perception \& Performance, 12, 370-379.

HOLENDER, D. (1986). Semantic activation without conscious identification in dichotic listening, parafoveal vision, and visual masking: A survey and appraisal. Behavioral \& Brain Sciences, 9, 1-23.

JACOBY, L. L. (1991). A process dissociation framework: Separating automatic from intentional uses of memory. Journal of Memory \& Language, 30, 513-541.

JACOBY, L. L., TOTH, J. P., \& YONELINAS, A. P. (1993). Separating conscious and unconscious influences of memory: Measuring recollection. Journal of Experimental Psychology: General, 122, 139-154.

Keefe, D. E., \& NeEly, J. H. (1990). Semantic priming in the pronunciation task: The role of prospective prime-generated expectancies. Memory \& Cognition, 18, 289-298.
LUCE, P. A. (1986). Neighborhoods of words in the mental lexicon. Unpublished doctoral dissertation, Indiana University, Bloomington, IN.

LuCe, P. A., Pisoni, D. B., \& Goldinger, S. D. (1990). Similarity neighborhoods of spoken words. In G. Altmann (Ed.), Cognitive models of speech processing (pp. 122-147). Cambridge, MA: MIT Press.

MaCmillan, N. A., \& Creelman, C. D. (1990). Response bias: Characteristics of detection theory, threshold theory, and "nonparametric" indexes. Psychological Bulletin, 107, 401-413.

Macmillan, N. A., \& Creelman, C. D. (1991). Detection theory: A user's guide. Cambridge: Cambridge University Press.

MARCEL, A. J. (1983). Conscious and unconscious perception: Experiments on visual masking and word recognition. Cognitive Psychology, 15, 197-237.

MARSLEN-WILSON, W. D. (1990). Activation, competition, and frequency in lexical access. In G. Altmann (Ed), Cognitive models of speech processing (pp. 148-172). Cambridge, MA: MIT Press.

McClelland, J. L., \& Elman J. L. (1986). The TRACE model of speech perception. Cognitive Psychology, 18, 1-86.

MCClelland, J. L., \& Rumelhart, D. E. (1981). An interactive activation model of context effects in letter perception: Part I. An account of basic findings. Psychological Review, 88, 375-405.

MCLEAN, J. P., \& ShULMAN, G. L. (1978). On the construction and maintenance of expectancies. Quarterly Journal of Experimental Psychology, 30, 441-454.

MCNicHOL, D. (1972). A primer of signal detection theory. London: Allen \& Unwin.

Meyer, D. E., \& Schvaneveldt, R. W. (1971). Facilitation in recognizing pairs of words: Evidence of a dependence between retrieval operations. Journal of Experimental Psychology, 90, 227-234.

MorTon, J. (1969). Interaction of information in word recognition. Psychological Review, 76, 165-178.

NeEly, J. H. (1977). Semantic priming and retrieval from lexical memory: Roles of inhibitionless spreading activation and limited-capacity attention. Journal of Experimental Psychology: General, 106, 226-254.

Neely, J. H. (1991). Semantic priming effects in visual word recognition: A selective review of current findings and theories. In D. Besner \& G. Humphreys (Eds.), Basic issues in reading: Visual word recognition (pp. 264-336). Hillsdale, NJ: Erlbaum.

NorRIs, D. (1995). Signal detection theory and modularity: On being sensitive to the power of bias models of semantic priming. Journal of Experimental Psychology: Human Perception \& Performance, 21, 935-939.

PaAP, K. R., Newsome, S. L. McDonald, J. E., \& Schwaneveldt, R. W. (1982). An activation-verification model for letter and word recognition: The word superiority effect. Psychological Review, 89, 573-594.

PosNer, M. I., \& SNYDER, C. R. R. (1975). Facilitation and inhibition in the processing of signals. In P. M. A. Rabbit \& S. Dornic (Eds.), Attention and performance $V$ (pp. 669-682). New York: Academic Press.

Radeau, M., Morais, J., \& Dewier, A. (1989). Phonological priming in spoken word recognition: Task effects. Memory \& Cognition, 17, 525-535.

Radeau, M., Morais, J., \& Segui, J. (1995). Phonological priming between monosyllabic spoken words. Journal of Experimental Psychology: Human Perception \& Performance, 21, 1297-1311.

RatClifF, R., MCKoON, G., \& VERWOERd, M. (1989). A bias interpretation of facilitation in perceptual identification. Journal of Experimental Psychology: Learning. Memory, \& Cognition, 15, 378-387.

Rhodes, G., Parkin, A. J., \& Tremewan, T. (1993). Semantic priming and sensitivity in lexical decision. Journal of Experimental Psychology: Human Perception \& Performance, 19, 154-165.

Seidenberg, M. S., Waters, G. S., Sanders, M., \& Langer, P. (1984). Pre- and postlexical loci of contextual effects on word recognition. Memory \& Cognition, 12, 315-328.

SekUler, R., \& Blake, R. (1990). Perception (2nd ed.). New York: McGraw-Hill.

Slowiaczek, L. M., \& HAmburger, M. (1992). Prelexical facilitation and lexical interference in auditory word recognition. Journal of Experimental Psychology: Learning, Memory, \& Cognition, 18, 1239-1250. Slowiaczek, L. M., Nusbaum, H. C., \& Pisoni, D. B. (1987). Phono- 
logical priming in auditory word recognition. Journal of Experimental Psychology: Learning, Memory, \& Cognition, 13, 64-75.

SlowiaczeK, L. M., \& PISONI, D. B. (1986). Effects of phonological similarity on priming in auditory lexical decision. Memory \& Cognition, 14, 230-237.

Treisman, M. (1978). A theory of the identification of complex stimuli with an application to word recognition. Psychological Review, 85, 525-570.

Webster's Seventh Collegiate Dictionary (1967). Los Angeles: Library Reproduction Service.

\section{NOTES}

1. One limitation of the Goldinger et al. (1992) study, as well as the present investigation, is that it examined phonemic priming in a very narrow sense. Specifically, we only tested prime-target pairs sharing one initial phoneme. As noted in the introduction, phonemic priming effects are quite different, depending on degrees of prime-target overlap (Slowiaczek \& Hamburger, 1992). Unfortunately, the comparison of feature and phonemic priming requires such minimal differences. Therefore, all claims about phonemic priming in the present article are directed to the one-phoneme overlap condition.

2 . In the present experiments, perceptual interactions were possible between spoken words and the visual response choices. For example, the response choices may create backward priming when spoken words are not perceptually resolved. However, such effects were equally likely in phonemic and feature priming, minimizing their possible impact on data interpretation.

3. Given the nonintuitive similarity relations between feature primes and targets, Goldinger et al. (1992) conducted an experiment to ensure that related pairs, such as LOB-ROPE, were considered perceptually similar, relative to unrelated pairs such as MUCH-ROPE. We conducted a same-different experiment: Listeners heard word pairs and quickly indicated whether they heard the same word twice or two different words. Half the trials were same, and half were different. Half the different trials were unrelated pairs, and half were feature pairs. Three conditions were run, with 40 subjects in each. In one condition, both words were presented in noise (as when Luce's [1986] confusion matrices were derived). In another condition, only the second word was presented in noise (as in the priming experiments). In a third condition, both words were presented in the clear. In all conditions, different responses were reliably slower and less accurate to feature pairs than to unrelated pairs. These data show that, although feature pairs such as LOB-ROPE do not sound particularly similar, they are more similar than their associated unrelated pairs

4. In Experiments 1-3, no clear predictions are available for the unrelated trials. If the hypothesized bias was applied without regard to perceptual clarity, unrelated trials (e.g., MUCH-ROPE) would generate only misses and correct rejections, as subjects would always respond "no." In reality, even biased subjects are quite unlikely to apply the phonemic bias to unrelated trials, because the initial phonemes of the spoken and visual words are so dissimilar. Therefore, the unrelated trials in Experiments 1-3 only serve to establish a baseline. However, the unrelated trials in Experiment 4 were used to indicate biases, as in Goldinger et al. (1992).

5. A variant of this strategy has recently been applied by Jacoby to disentangle automatic and controlled aspects of recall (Jacoby, 1991; Jacoby, Toth, \& Yonelinas, 1993). The process-dissociation framework uses a method of opposition, wherein memory components compete to elicit orthogonal responses.

APPENDIX

Stimuli Used in All Experiments

\begin{tabular}{|c|c|c|c|c|c|c|c|}
\hline Targets & $\begin{array}{l}\text { Related } \\
\text { Primes }\end{array}$ & $\begin{array}{c}\text { Unrelated } \\
\text { Prime }\end{array}$ & Catch Foils & Targets & $\begin{array}{l}\text { Related } \\
\text { Primes }\end{array}$ & $\begin{array}{c}\text { Unrelated } \\
\text { Prime }\end{array}$ & Catch Foils \\
\hline LATE-RATE & RASH-LASH & MISS & mate-nate & PALM-CALM & CAN-PAN & SOURCE & sash-bash \\
\hline WAD-ROD & WRIT-WIT & NIECE & $\operatorname{nod}-\bmod$ & SAP-CHAP & CHICK-SICK & NEED & nap-map \\
\hline PUTT-CUT & COUCH-POUCH & GENE & jut-gut & BUN-DONE & DAM-BOMB & SET & sun-shun \\
\hline WED-RED & ROOM-WOMB & FATE & fed-shed & HERB-CURB & CAD-HAD & VAGUE & verb-serb \\
\hline RISE $\rightarrow$ LIES & LACE-RACE & PEEK & pies-ties & PUN-TON & TOM-POM & FIZZ & fun-shun \\
\hline PILE-TILE & TOUR-POUR & RACE & while-rile & LIMB-RIM & RAIN-LANE & CASH & kim-dim \\
\hline NUT-MUTT & MATCH-NOTCH & WILL & what-shut & PUB-TUB & TAD-PAD & SCENE & sub-chub \\
\hline CARE-TEAR & TILL-KILL & WING & wear-lair & WADE-RAID & ROBE-WEB & JOCK & jade-shade \\
\hline FOOL-TOOL & TEA-FEE & RAGE & rule-yule & BOOM-DOOM & DEAN-BEAN & WHALE & womb-room \\
\hline FEAR-PEER & PULL-FULL & LINK & leer-rear & NOOSE-MOOSE & MOAT NOTE & LEAGUE & lose-use \\
\hline TOOK-COOK & COUTH-TOOTH & LEASE & look-rook & TOAD-CODE & CUBE-TUBE & LULL & load-road \\
\hline PIPE-TYPE & TOKE-POKE & REACH & ripe-wipe & BUG-DUG & DID-BID & LANE & lug-rug \\
\hline BALL-FALL & FAR-BAR & MASH & mall-wall & MUM-NUMB & NOR MORE & HAT & hum-sum \\
\hline HIRE-TIRE & TAIL-HAIL & WAKE & wire-liar & WAG-RAG & RIDE-WIDE & HOPE & hag-shag \\
\hline PIN-TIN & TONG-PONG & SAIL & sin-shin & YACHT-WATT & WOKE-YOKE & DEAR & dot-pot \\
\hline BILL-DILL & DARE-BARE & WET & will-mill & PACK-TACK & TODD-POD & SEAL & sack-shack \\
\hline TEN-KEN & KIM-TIM & ROACH & wren-yen & POSE-TOES & TIE-PIE & HOWL & head-fed \\
\hline PINE-TINE & TOME-POEM & SHELL & shine-whine & JOT-GOT & GAWK-JERK & NINE & not-tot \\
\hline HOT-TOT & TALK-HAWK & RANG & rot-lot & POISE-TOYS & TOSS-PEACE & NAME & noise-joys \\
\hline GET-DEBT & DASH-GASH & LOOM & let-yet & KEG-PEG & $P A D-C A D$ & LEECH & leg-beg \\
\hline PICK-TICK & TUG-PUG & CHEESE & chick-sick & CORN-BORN & BANG-KING & WASH & worn-horn \\
\hline NEAR-MERE & MOLE-KNOLL & CHAIN & cheer-sheer & YAP-RAP & RACK-YAK & SAGE & sap-tap \\
\hline NOTE-MOAT & MITCH-NICHE & GEESE & goat-tote & MOB-KNOB & NAG-MUG & SIZE & sob-job \\
\hline GONE-DAWN & DAME-GAME & PUSH & pawn-fawn & PURSE-CURSE & COT-POT & WHALE & worse-nurse \\
\hline SAD-BAD & BAIT-SATE & LOON & lid-rid & WIG-RIG & RUDE-WOULD & PORCH & pig-dig \\
\hline NOON-MOON & $\mathrm{ME}-\mathrm{KNEE}$ & DIRT & dune-goon & RUG-LUG & LOAD-ROAD & MANE & mug-thug \\
\hline MOOD-NUDE & NAY-MAY & FEATURE & food-chewed & SHONE-TONE & TAME-SHAME & $\mathrm{LAG}$ & lone cone \\
\hline
\end{tabular}


APPENDIX (Continued)

\begin{tabular}{|c|c|c|c|c|c|c|c|}
\hline Targets & $\begin{array}{c}\text { Related } \\
\text { Primes }\end{array}$ & $\begin{array}{c}\text { Unrelated } \\
\text { Prime }\end{array}$ & Catch Foils & Targets & $\begin{array}{l}\text { Related } \\
\text { Primes }\end{array}$ & $\begin{array}{c}\text { Unrelated } \\
\text { Prime }\end{array}$ & Catch Foils \\
\hline MORE-NOR & NULL-MULL & SOUTH & sore-shore & GORE-BORE & BAIL-GAIL & SHEATH & shore-fore \\
\hline YORE-GORE & GULL-YELL & PEEP & pore-bore & DUMB-GUM & GOWN-DOWN & SOAP & sum-chum \\
\hline FORK-PORK & PUT-FOOT & YOUNG & york-cork & RUT-WHAT & WOKE-ROOK & MAN & mutt-nut \\
\hline LOPE-ROPE & ROB-LOB & $\mathrm{MUCH}$ & mope-nope & RAM-YAM & YOUNG-RUNG & HUSH & ham-sam \\
\hline FOAM-COMB & CANE-FEIGN & LURCH & loam-roam & SHARE-CHAIR & CHILL-SHELL & DOPE & dare-pair \\
\hline FIRM-TERM & TAN-FAN & WHICH & worm-germ & FED-BED & BIB-FIB & LosS & led-red \\
\hline SHOP-CHOP & CHAT-SHUT & BOWEL & bop-top & SHIP-CHIP & CHALK-SHOCK & RAKE & rip-whip \\
\hline SHORE-CHORE & CHEW-SHOE & NAME & nor-more & CAR-PAR & POOL - COOL & GYM & jar-far \\
\hline LOSE-BOOZE & BEAD-LEAD & NOW & news-dues & BATH-PATH & PUCK-BUCK & REEL & wrath-math \\
\hline NINE-MINE & MODE-NODE & SIT & sign-line & $\mathrm{TOP}-\mathrm{COP}$ & CUFF-TOUGH & SEER & sop-hop \\
\hline VET-BET & BIRD-VOID & WON & wet-yet & CALF-HALF & $\mathrm{HASH}-\mathrm{CASH}$ & LOOP & laugh-chaff \\
\hline BUZZ-DOES & DOSE-BOSS & WALL & was-fuzz & HEN-TEN & TONGUE-HUNG & YOLK & yen-when \\
\hline $\mathrm{CAB}-\mathrm{TAB}$ & TOLD-COLD & LOIN & lab-nab & CALL-PALL & PORE-CORE & HAM & hall-fall \\
\hline NAP-MAP & MOCK-KNOCK & GOOSE & gap-cap & PAR-TAR & TOLL-POLL & GAIN & gar-car \\
\hline VEER-BEER & BULL-VEIL & GOON & gear-tear & RUSH-LUSH & LATCH-RICH & MIME & mush-hush \\
\hline LIP-RIP & RAKE-LAKE & TASTE & tip-dip & FOUGHT-SOUGHT & SAKE-FAKE & BARGE & bought-wrought \\
\hline MITT-KNIT & KNACK-MACK & WEAVE & wit-lit & HURT-PERT & PATCH-HATCH & DIAL & dirt-curt \\
\hline WIPE - RIPE & RAKE-WAKE & HORSE & hype-type & GEAR-YEAR & YULE-GHOUL & FIN & fear-shear \\
\hline PUS-CUSS & COKE-POKE & MORGUE & muss-fuss & HOOD-COULD & CUB-HUB & WASH & wood-good \\
\hline SHIN-CHIN & CHIME-SHAME & PEEL & pin-kin & SAID-FED & FIB-SUB & ROAR & red-wed \\
\hline MICE-NICE & NOSE-MAZE & LOOK & lice-rice & MAT-GNAT & NOPE-MOPE & WREAK & rat-vat \\
\hline
\end{tabular}

Note-Catch foils were used only in Experiment 4.

(Manuscript received December 6, 1996;

revision accepted for publicaton August 17, 1997.) 